\title{
DYSPHAGIA PRODUCED BY CERVICAL SPINE OSTEOPHYTE. A CASE REPORT
}

\author{
DISFAGIA PRODUZIDA POR OSTEÓFITO DA COLUNA CERVICAL. RELATO DE CASO
}

DISFAGIA PRODUCIDA POR OSTEOFITO DE COLUMNA CERVICAL. A PROPÓSITO DE UN CASO

Claudio Silveri ${ }^{1}$, Juan Manuel Velasco ${ }^{1}$, Asdrúbal Silveri ${ }^{1}$

\begin{abstract}
We present a case of a 73-year-old male patient with progressive dysphagia, and hoarseness (irritability in the throat). He was studied with the appropriate imaging techniques, and esophagoscopy led to a diagnosis of extrinsic esophageal dysphagia for osteophyte obstruction of the cervical spine due to the arthrosis. A surgical resection was performed, without complications. Some considerations are given on this theme.
\end{abstract}

Keywords: Cervical spine; Dysphagia; Ostheophyte.

\section{RESUMO}

Apresentação de caso de paciente com 73 anos de idade e história de disfagia progressiva, com intercorrência de rouquidão (irritação na garganta). O caso foi analisado com técnica de imagem adequada, incluindo esofagoscopia, estabelecendo-se o diagnóstico de disfagia extrínseca por obstrução com osteófito da coluna vertebral cervical decorrente de artrose. Realizou-se a ressecção cirúrgica sem complicações. Apresentam-se algumas considerações sobre o caso.

Descritores: Coluna cervical; Disfagia; Osteófito.

\section{RESUMEN}

Se presenta un caso de un paciente de 73 años de edad, de sexo masculino, con historia de disfagia progresiva, a la cual se agregó carraspera (irritación en la garganta). Luego de ser estudiado con imagenología adecuada, y estudio esofagoscópico se estableció el diagnostico de disfagia extrínseca, compresiva por osteofito de la columna cervical debido a artrosis. Se realizó la resección quirúrgica sin complicaciones. Se realizan algunas consideraciones sobre el tema.

Descriptores: Columna cenvical; Disfagia; Osteofito.

\section{INTRODUCTION}

Dysphagia is a swallowing disorder that manifests as difficulty passing the food bolus through the esophagus. It is a frequent cause of medical appointments.

Asymptomatic osteophytes of the anterior borders of the cervical vertebrae may occur in twenty to thirty percent of the population. ${ }^{1}$

Although cervical spondylosis and dysphagia are frequent and common problems in the elderly, there is usually no connection between them. In cases where they coexist in the same patient, an adequate and precise investigation should be carried out, to avoid misdiagnoses. Mosher ${ }^{2}$, in 1926, was the first to describe dysphagia caused by osteophytes.

This infrequent association includes a series of nonsurgical therapeutic measures. When these fail, adequate surgical decompression can reestablish normal function of the esophagus.

This work presents a case of extrinsic dysphagia caused by cervical spine osteophytosis.

\section{CLINICAL CASE}

A retired 73-year-old patient, with a history of dizziness, who consults the ENT. Cervical spine X-ray is requested for this patient. The findings show dysphagia with one year of evolution that have made it difficult for him to swallow solid food and/or tablets, a symptom that has recently become more intense and has caused a certain degree of hoarseness.
Upon examination the patient had no neurological signs in the upper or lower limbs. There were no signs of arthrotic cervical myelopathy. The patient reported mechanical low back pain that responded to medical and physiatric therapeutic measures.

The patient underwent an X-ray (Figure 1) showing a thick disc osteophyte at level C4-C5 without disc impingement and below in space C6-C5 appears almost fused. The rest of the spine exhibits arthrotic elements.

CT scan (Figure 2) showed the osteophyte and the arthrotic facet joints.

MRI (Figures 3A, 3B and $3 \mathrm{C}$ ) showed spinal canal with normal dimensions. Thick anterior osteophyte at C4-C5 that deforms the common anterior vertebral ligament and leaves a notch on the airway, pushing the hyoid bone. The esophagus appears lateralized and compressed.

In the pre-surgical anesthetic induction, a bronchoscopy was performed to intubate the patient, followed by an esophagoscopy to accurately determine the topography of the esophagus, and its location in relation to the osteophyte, and to view the protrusion of the extrinsic process. (Figure 3B)

The surgery was performed via an anterolateral approach in the neck using the usual technique, moving the carotid sheath laterally and the visceral axis medially. The prevertebral fascia was exposed in a relatively avascular manner. A thick osteophyte was identified that was resected. Resection was confirmed by X-ray. Wax and gelfoam were applied to the bed. Fusion was not 


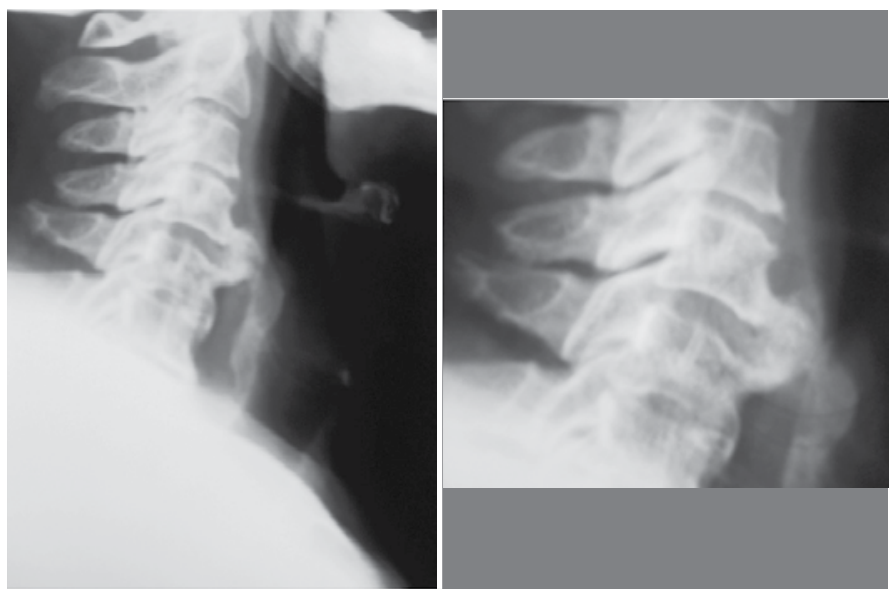

Figure 1. Osteophyte C4-C5.

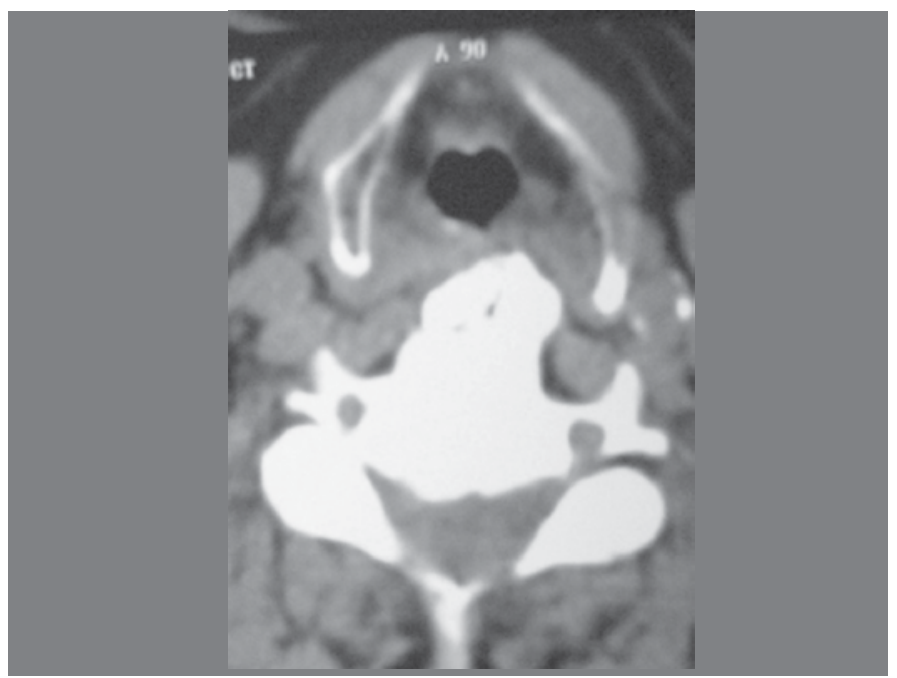

Figure 2. CT scan showing the osteophyte and the visceral compression.

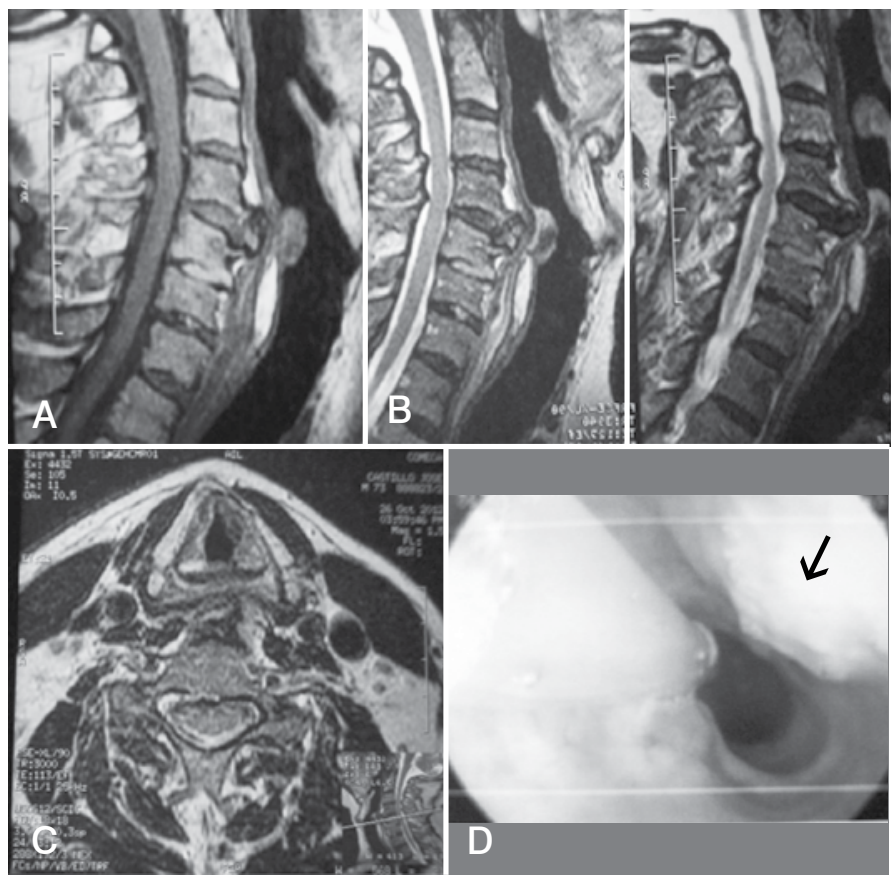

Figures 3. $A, B, C) M R$ of the anterior compression; D) Shows the esophagoscopy where we can see the displaced esophagus and the compression. performed. Continuity of the esophagus was verified, a suction drainage tube introduced, and the incision closed by planes. No external fixation was used.

Great caution should be taken to avoid causing involuntary damage to the esophagus, which may be inflamed and displaced. This is why we routinely perform previous esophagic intubation. The osteophytes are extirpated using a chisel and rongeurs. It is possible to use a drill, performing careful hemostasis (apply wax) because the bed may be very bloody and produce complications due to compressive hematoma of neighboring structures (trachea and/or esophagus), also leaving a suction drainage tube during the first postoperative hours.

The patient evolved without complications; there was no dysphonia or surgical site infection, and the patient was discharged 48 $\mathrm{h}$ after surgery using a cervical collar for analgesic purposes.

\section{DISCUSSION}

Degenerative cervical spine disease (cervical spondylosis) is a relatively common condition, especially in patients of advanced age.

The bone abnormalities associated with degenerative cervical disease are frequently produced on the posterior surface of the cervical vertebral body, and this often produces compression of the spinal cord or of nerve roots with the consequent neurological manifestations (neuropathy or myelopathy) - although anterior osteophytes that are usually asymptomatic are frequently associated.

The incidence of arthrosis and dysphagia increases among elderly individuals and may coexist. When this occurs, it presents a diagnostic and therapeutic dilemma.

The challenge continues to be determining with certainty whether dysphagia is caused by the mechanical compression of the esophagus by cervical osteophytes, or by other causes.

Dysphagia caused by mechanical compression generated by anterior cervical osteophytes has been described by countless authors, ${ }^{3-5}$ although some believe that dysphagia in a patient with cervical osteophyte disease is purely incidental. Others believe that because the esophagus starts at level $\mathrm{C} 6$, it is impossible to establish a cause and effect relationship between dysphagia and cervical osteophytes above this level.

The most likely mechanism of dysphagia would be its interference in swallowing in the pharingoesophageal junction, although osteophytes in the lower cervical spine can also interfere with esophageal peristalsis.

The degree of dysphagia ${ }^{6}$ is classified as mild, moderate or severe. Mild dysphagia is defined as an abnormal sensation (for example, a sensation of a foreign body or of slight pain) in the pharynx while swallowing solids or liquids. Patients with moderate dysphagia have difficulty swallowing solid boluses, although patients are able to swallow small amounts of liquids without difficulty. This is our case.

Several mechanisms have been described whereby an osteophyte can generate dysphagia. Firstly, a large osteophyte may cause direct mechanical obstruction of the esophagus or hypopharynx. Secondly, dysphagia may be caused by small osteophytes, if they are located at fixed points in the esophagus (cricoid cartilage at level C6). Thirdly, osteophytes may cause an inflammatory reaction around the esophagus or a compression neuropathy. In rare cases, such as the one analyzed in this study, a large osteophyte produced slow-progressing chronic dysphagia that had previously received conservative treatment.

The most frequent bibliographic records found in the medical literature link these clinical pictures to Forestier's disease or diffuse idiopathic skeletal hyperostosis ${ }^{6-10}$ and to a lesser degree, with osteophytes of arthrotic origin.

The diagnosis should be preceded by a thorough imaging study that includes simple X-ray, CT scan, MRI, barium esophagram and esophageal endoscopy. Patients should undergo an appropriate ENT and endoscopic examination.

CT scans can show more precise details of the three-dimensional 
relationship between the esophagus and the spine. Esophagoscopy should be used with considerable caution in these patients, as the posterior pharyngeal and esophageal wall may be thin, and the risk of perforation increased.

It is important to stress that the patient had anesthesia induced by a bronchoscopist to avoid injury due to displacements of the visceral axis. We consider it important to introduce a nasogastric tube during surgery allowing the surgeon to better locate the esophagus and to palpate it during the release of the osteophyte.

The interesting aspect of our case is that there is an osteoarthritic process between $\mathrm{C} 4$ and $\mathrm{C} 5$, with disc preservation and a clearly evident arthrotic process in the posterior facet joint with facet joint edema and subluxation (visible in the MRI), which is above a space (C5-C6) that is almost fused. We suspect this may have favored the formation of the osteophyte on a more mobile disc:

This process differs from those produced by calcification of the anterior longitudinal ligament (enthesitis), as seen in Forestier's disease.
Resection should be performed through an anterior route with the usual approach, resecting the osteophyte with a chisel, rongeurs or drill. Miyamoto et al. ${ }^{(10)}$ demonstrated that if we perform the resection of an anterior vertebral cervical osteophyte, it can be regenerated with average growth of $1 \mathrm{~mm}$ per year.

The seven patients referred to in this study developed radiological recurrence of cervical osteophytes (width $>2 \mathrm{~mm}$ ) within 4 years after resection of the osteophytes.

Anterior marginal osteophytosis should be included among the differential diagnoses of dysphagia in elderly adult patients. When conservative treatments have failed and compressive mechanical process is a certainty, this surgical solution can restore digestive function.

All authors declare no potential conflict of interest concerning this article.

\section{REFERENCES}

1. Kissel P, Youmans JR. Posttraumatic anterior cervical osteophyte and dysphagia: surgical report and literature review. J Spinal Disord. 1992;5(1):104-7.

2. Mosher HP. Exostoses of the cervical vertebrae as a cause for difficulty in swallowing Laryngoscope. 1926:36:181-2.

3. Kodama M, Sawada H, Udaka F, Kameyama M, Koyama T. Dysphagia caused by an anterior cervical osteophyte: case report. Neuroradiology. 1995;37(1):58-9.

4. Gamache FW Jr, Voorhies RM. Hypertrophic cervical osteophytes Rausing dysphagia. A review. J Neurosurg. 1980;53(3):338-44.

5. Brandenberg G, Leibrock LG. Dysphagia and dysphonia secondary to anterior cervical osteophytes. Neurosurgery. 1986;18(1):90-3.

6. Miyamoto K, Sugiyama S, Hosoe H, linuma N, Suzuki Y, Shimizu K. Postsurgical recur- rence of osteophytes causing dysphagia in patients with diffuse idiopathic skeletal hyperostosis. Eur Spine J. 2009;18(11):1652-8.

7. Urrutia J, Bono CM. Long-term results of surgical treatment of dysphagia secondary to cervical diffuse idiopathic skeletal hyperostosis. Spine J. 2009;9(9):e13-7.

8. Presutti L, Alicandri-Ciufelli M, Piccinini A, Trebbi M, Marchioni D, Ghidini A, et al. Forestier disease: single-center surgical experience and brief literature review. Ann Otol Rhinol Laryngol. 2010;119(9):602-8.

9. Granville LJ, Musson N, Altman R, Silverman M. Anterior cervical osteophytes as a cause of pharyngeal stage dysphagia. J Am Geriatr Soc. 1998;46(8):1003-7.

10. Song AR, Yang HS, Byun E, Kim Y, Park KH, Kim KL. Surgical treatments on patients with anterior cervical hyperostosis-derived Dysphagia. Ann Rehabil Med. 2012;36(5):729-34. 